\title{
The First Stage of Developing the Adolescent Friendship Social Capital Scale
}

\author{
Leilei $\mathrm{Xu}^{*}$ \\ Deakin University
}

\begin{abstract}
The purpose of the study was to generate the candidate items for the Adolescent Friendship Social Capital Scale. Both inductive and deductive approaches were used to generate the scale items. Halpern's conceptual map of social capital served as the theoretical basis of this scale, and guided the development of items. Semi-structured interviews with adolescents in Sydney, Melbourne and Beijing generated the initial pool of scale items. Twenty-six items were generated for the Adolescent Friendship Social Capital Scale. The items are organised in four theoretical constructs: Bonding Networks, Bridging Norms, Bridging Sanctions, and Linking Networks. Each item is a short statement followed by a five-point Likert scale anchored by $1=$ "Strongly disagree" and $5=$ "Strongly agree". The scale has several advantages over previous measures of adolescent friendship networks and friendship social capital. The scale has a strong and clear theoretical structure, the scale items demonstrate initial construct and content validity, and the format of the scale enables the collection of continuous data. However, in order to ensure the validity and reliability of the scale, another two stages of research need to be conducted in the future: scale development and scale evaluation.
\end{abstract}

Keywords : adolescent, friendship networks, scale development, item generation, friendship social capital

Children and young people need friends. For very young children, friends are partners and playmates with whom time is spent and interesting activities can be pursued (Ginsberg, Gottman, \& Parker, 1986). When they grow older, they need friends not only to do things together, but also to obtain help and support from each other (Bernt, 1989). During adolescence, friendship becomes more important, as 'adolescents believe that they learn more about reality and about themselves from their friends than from anyone else. Indeed, it is within friendship that adolescents feel least as if

* Corresponding Author: Leilei Xu, Research Fellow, School of Architecture and Building, Deakin University, Gheringhap Street, Geelong, VIC 3220, Australia. E-mail: xuleilei98 @gmail.com they are living out a role and most like themselves - the personalities they believe themselves to be' (Youniss \& Smollar, 1985, p. 143).

Friendship networks contribute substantially to adolescents' social and cognitive developments. Close friends provide social supports and coping assistances against potential stresses that adolescents cannot comfortably discuss with parents (Seiffge-Krenke, 1993). Peer groups provide valuable networks through which adolescents' personal identities and selfesteems are developed. Peer groups also influence adolescents' social behaviours, attitudes and academic adjustments (Plata \& Trusty, 2005). 
A major hindrance to research on adolescent friendship network has been the lack of a reliable method of assessment, in that no psychometrically sound instrument has been developed to measure an adolescent's friendship networks. Previous measures have been inconsistent across studies, and it is difficult to compare the processes and results between studies. In addition, the existing measurement tools have not been informed by the social capital theory, which offers a powerful framework to conceptualise social networks. Therefore, this study sets out to fill the gap in the literature. The ultimate aim of this study is to develop a psychometrically sound instrument to measure an adolescent's friendship social capital, which will involve three stages: Item Generation, Scale Development, and Scale Evaluation (Hinkin, 1995). The process and results presented in this paper is the first stage of the study: Item Generation. A combination of deductive and inductive approaches was used, in that the items were generated both from theory and empirical field research.

In the following sections, the author briefly traces the roots of social capital theory and adopts Halpern's conceptual map of social capital as the theoretical basis of this scale. Based on the Halpern's conceptual map, the author criticises previous measures of an adolescent's friendship networks and friendship social capital. After that, she presents the item generation process of this study. At the end of the paper, she discusses the strengths and limitations of the scale and proposes the direction of future research.

\section{Theoretical Basis of the Scale: Halpern's Ecological Model of Social Capital}

Social capital theory treats social relationship as a resource, and it offers a powerful tool to conceptualise social networks. The social capital metaphor is that people who do better are somehow better connected. Each person holds a position in a certain network, in that the person is connected to certain others, trusting certain others, obligated to support certain others and dependent on exchange with certain others. Holding a position in a network is an asset in its own right, and that asset is social capital (Burt, 2000).

Social capital theory was first introduced by Pierre Bourdieu (Bourdieu, 1972), developed and popularised by James Coleman (Coleman, 1988, 1990), and achieved public awareness through the work of Robert Putnam (Putnam, 2000; Putnam, Leonardi, \& Nanetti, 1993). Each of the three key authors (Bourdieu, Coleman, \& Putnam) offered seminal contributions to the development of the concept. Bourdieu's early writings during the 1970s and 1980s set the ontological assumptions of the concept. He wrote within a Marxist framework and distinguished three forms of capital: economic, cultural and social (Bourdieu, 1986). Bourdieu considered social capital as a form of resource possessed by individuals. His treatment of social capital emphasised how the privileged individuals maintain their positions by using their connections with other privileged people (Field, 2003).

Coleman pointed out that people from nonelite groups could also benefit from the possession of social capital. His definition of social capital emphasised on its function. According to him, social capital consists some aspects of social structures, and facilitates the actions of actors within social structures (Coleman, 1988; Field, 2003).

Drawing on a range of theories and empirical data, Robert Putnam's (1995, 2000) analyses of social capital in the United States reached wider audience. One of his contributions to the theory of social capital was that he distinguished between two types of social capital: bonding and bridging. Bonding social capital is inward looking and echoes the 'strong ties' between family members and close friends; while bridging social capital is outward looking and echoes the 'weak ties' between acquaintances (Granovetter, 1973, 1985; Halpern, 2005; Putnam, 2000).

Putnam's (1995, 2000) writings of the declining social capital in the United States lighted a major spark to the literature, and there 
have been an explosion in the use of the term 'social capital' since 1995 (Halpern, 2005). Attempts have been made to refine and develop our theoretical understandings of social capital. For example, Michael Woolcock (2001), a social scientist with the World Bank distinguished between three types of social capital: bonding, bridging and linking. The additional type, linking social capital, describes the social connections between those with very unequal power and resources.

It is now also understood that social capital is a multi-level concept, which ranges from the macro-level (e.g., social networks of nations) to micro-level (e.g., social connections of an individual person). There have been empirical studies that used the concept of social capital to analyse the social capital of nations (e.g., von dem Knesebeck, Dragano, \& Siegrist, 2005), organisations (e.g., Brien \& Smallman, 2011), neighbourhoods (e.g., Slund, Starrin, \& Nilsson, 2010), families (e.g., Wu, Palinkas, \& He, 2011), and individuals (e.g., Chen, Stanton, Gong, Fang, \& Li, 2009).

Frameworks have been proposed to critically synthesise the work of the three fathers and their followers (e.g., Lin, 2001; Schaefer-McDaniel, 2004). Among these frameworks, Halpern's conceptual map of social capital is probably the most structured and comprehensive one. Halpern's (2005, p. 27) conceptual map of social capital shows that social capital should be analysed at three ecological levels: micro, meso and macro. Building upon Putnam's (2000) and Woolcock's (2001) analyses of types of social capital, Halpern's model distinguishes the bonding, bridging, and linking social capital. In addition, his model proposes that there are three components of social capital: networks, norms and sanctions. Norms are the rules, values and expectancies that shared by network members; and sanctions are the punishments and rewards that help to maintain the norms and networks.

As this study aims to develop a psychometrically sound measurement of an individual adolescent's friendship social capital, Halpern's conceptual map at micro level was adopted as the theoretical basis of the scale. As shown in Figure 1, an adolescent's social capital has nine theoretical constructs: Bonding networks, bonding norms, bonding sanctions, bridging networks, bridging norms, bridging sanctions, linking networks, linking norms, and linking sanctions. Mostly adopted from Halpern's model with minor modifications, examples are given to the theoretical constructs. For example, 'close friends' is given as an example of 'bonding networks', and 'reciprocity' is given as an example of 'bridging norms'. The examples are for illustrative purpose, and could be revised and modified through empirical interviews with adolescents.

The conceptual map of an adolescent's friendship social capital (Figure 1) provides a

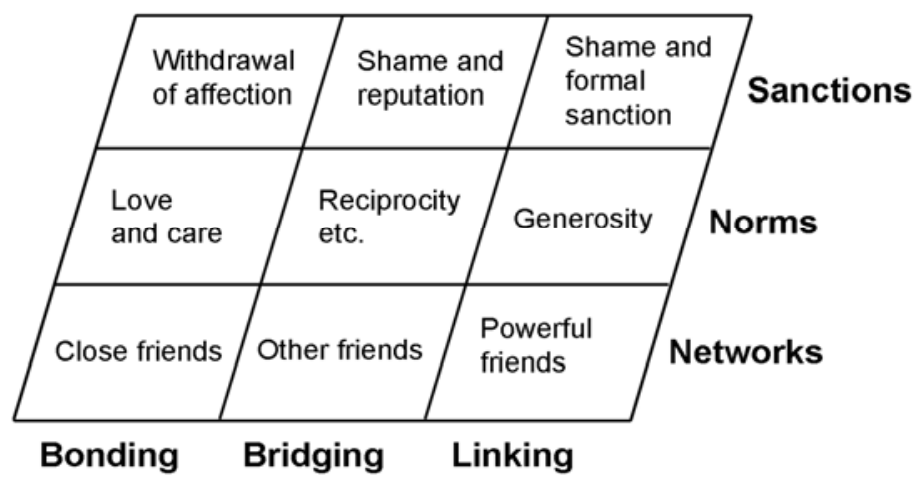

Figure 1. An adolescent's friendship social capital (with examples). It is based on Halpern's conceptual map of social capital (Halpern, 2005; p. 27). 
theoretical framework that will guide the arguments in the following sections of this paper. It offers a pair of glasses through which we look at the literature, and it guides the item generation process of this study.

\section{Limitations of Previous Measures of Adolescent Friendship Social Capital}

Halpern's conceptual map of social capital offers a powerful framework to conceptualise social networks. However, most of the existing measurements of adolescents' friendship networks have not been informed by this framework. Social cognitive mapping (SCM) was used in many studies to assess adolescents' peer group affiliations (e.g., Berger \& Rodkin, in press; Hamm, Farmer, Dadisman, Gravelle, \& Murray, 2011). SCM derives peer group affiliations by aggregating reports of all members of a classroom, thus identifying and characterising peer groups. For example, participants are asked to write down the names of the peers with whom they hang around together with a lot. The draw back of SCM is that it only investigates the 'network' component of an adolescent's friendship social capital, and does not collect information about the 'norms' and 'sanctions'.

The original and revised version of Parker and Asher's (1993) Friendship Quality Scale has been adopted by several empirical studies (e.g., Rose \& Asher, 1999; Rose, Swenson, \& Carlson, 2004). The Friendship Quality Scale is a multi-item measurement that assesses friendship dimensions such as validation and caring, conflict resolution, conflict and betrayal, etc. However, it is designed to assess the dyadic friendship quality between the respondent and one particular friend (in most cases, 'the very best friend'), and cannot assess the quality of the respondent's overall friendship networks. Another widely use scale (e.g., adopted by Cillessen, Jiang, West, \& Laszkowski, 2005), the Friendship Qualities Scale developed by Bukowski, Hoza and Boivin (1994) has the same limitation.

The Friendship and Peer Relations Interview was developed by Zimmermann (2004) to assess adolescents' friendship and peer relations. The semi-structured interview takes around 45 minutes and contains questions such as experiences and expectations in close peer relations, wider peer relations, and emotional regulations in close and wider peer relations. Compared to other measurement tools, this technique allows the investigator to obtain a much more complete picture of an adolescent's friendship networks. However, it is timeconsuming and costing. In addition, it collects qualitative data in the format of texts, which makes it difficult to investigate the relationships between an adolescent' friendship networks and other behavioural variables.

In Ryabov's (2011) investigation between peer effect and adolescents' academic achievement, he used the term 'peer social capital' and developed proxies to measure it. He used race segregation as the proxy of the structural component of peer social capital, and used the mean academic achievement of group members as the proxy of the quality component of peer social capital. Although his attempt of distinguishing the structural and quality components of peer social capital was worthwhile, the proxies he used have little connections with the theory of social capital.

In order to overcome the limitations of previous measurements, this study attempts to develop a tool to quantitatively measure an adolescent's friendship social capital. The following section reports the item generation process, using the conceptual map of social capital as the theoretical basis.

\section{Method}

\section{Research Design}

This study was designed as semi-structured interviews, guided by the conceptual map of social capital. The initial construct and content validity of the scale were established through this process. The themes emerged from the interview data fit into the theoretical constructs; 
therefore, the initial construct validity was established (the detailed process of identifying themes is elaborated in a following section).

Content validity concerns the item sampling adequacy, that is, the extent to which a specific set of items reflects the content domain (Devellis, 1991). The literature has suggested the use of content experts to increase the content validity of measurements (e.g., Coolican, 2004; Grant \& Davis, 1997; Moore \& Sugiyama, 2007). In this study, adolescents were regarded as experts of their social networks. Therefore, obtaining their opinions of the items was essential in the item generation process. Data collected from the interviews were analysed iteratively, in that the items generated from previous interviews were checked with respondents during the following interviews. The investigator also discussed with the respondents about the representativeness of the scale items and the clarity of the item statement, and made modifications to the items according

Table 1

Background Information of the Interview Respondents

\begin{tabular}{|c|c|c|c|c|c|}
\hline ID & $\begin{array}{l}\text { Interview } \\
\text { Location }\end{array}$ & $\begin{array}{l}\text { Interview } \\
\text { Language }\end{array}$ & Gender & Age & Cultural Background \\
\hline Sydney-1 & Sydney & English & $\mathrm{M}$ & 12 & Anglo-Celtic \\
\hline Sydney-2 & Sydney & English & $\mathrm{F}$ & 12 & Anglo-Celtic \\
\hline Sydney-3 & Sydney & English & $\mathrm{F}$ & 12 & Anglo-Celtic \\
\hline Sydney-4 & Sydney & English & $\mathrm{F}$ & 15 & Anglo-Celtic \\
\hline Sydney-5 & Sydney & English & M & 15 & Anglo-Celtic \\
\hline Sydney-6 & Sydney & English & M & 14 & Indian \\
\hline Sydney-7 & Sydney & English & M & 11 & Chinese \\
\hline Sydney-8 & Sydney & English & $\mathrm{F}$ & 10 & Chinese \\
\hline Sydney-9 & Sydney & English & $\mathrm{F}$ & 11 & Anglo-Celtic \\
\hline Sydney-10 & Sydney & English & $\mathrm{F}$ & 14 & Anglo-Celtic \\
\hline Melbourne-1 & Melbourne & English & M & 11 & Chinese \\
\hline Melbourne-2 & Melbourne & English & M & 11 & Anglo-Celtic \\
\hline Melbourne-3 & Melbourne & English & M & 13 & Anglo-Celtic \\
\hline Melbourne-4 & Melbourne & English & M & 13 & Chinese/European \\
\hline Melbourne-5 & Melbourne & English & $\mathrm{F}$ & 11 & Chinese \\
\hline Beijing-1 & Beijing & Chinese & $\mathrm{F}$ & 14 & Chinese \\
\hline Beijing-2 & Beijing & Chinese & $\mathrm{F}$ & 15 & Chinese \\
\hline Beijing-3 & Beijing & Chinese & M & 16 & Chinese \\
\hline Beijing-4 & Beijing & Chinese & $\mathrm{F}$ & 14 & Chinese \\
\hline Beijing-5 & Beijing & Chinese & $\mathrm{M}$ & 14 & Chinese \\
\hline Beijing-6 & Beijing & Chinese & $\mathrm{M}$ & 16 & Chinese \\
\hline Beijing-7 & Beijing & Chinese & $\mathrm{F}$ & 15 & Chinese \\
\hline Beijing-8 & Beijing & Chinese & $\mathrm{M}$ & 16 & Chinese \\
\hline Beijing-9 & Beijing & Chinese & M & 12 & Chinese \\
\hline Beijing-10 & Beijing & Chinese & $\mathrm{F}$ & 14 & Chinese \\
\hline
\end{tabular}


to their responses. Therefore, the initial content validity was built into the scale through this process.

\section{Participants}

The method of convenience was used to recruit interview participants: the investigator interviewed the children and young people through the connections of her family, friends and colleagues. The interview respondents included ten children from Sydney, five children from Melbourne, and ten children from Beijing. The investigations in Sydney and Melbourne were conducted in English, and the investigations in Beijing were conducted in Chinese. The respondents' gender, age and cultural background information is listed in Table 1. In order to protect the respondents' privacy, their names were replaced by IDs such as Sydney-1.

\section{Theoretical Constructs \& Interview Questions}

The conceptual map of social capital suggests that adolescent friendship social capital at individual level has nine theoretical constructs: Bonding networks, bonding norms, bonding sanctions, bridging networks, bridging norms, bridging sanctions, linking networks, linking norms, and linking sanctions. Assessing these nine dimensions will provide a complete picture of the respondents' social capital.

However, due to limited time and resource, the investigator decided to choose three constructs to develop the indicators: Bonding networks, bridging norms, and linking sanctions (as shown in Figure 2). The theoretical constructs were chosen based on two guidelines. Firstly, they should include the three types and three components of social capital. Secondly, their distribution in the model should be geometrically balanced, which indicates a good representation of the social capital concept.

Based on the chosen theoretical constructs highlighted in Figure 2, a set of interview questions was prepared but can be modified during the interview process. The questions investigate an adolescent' close friends (bonding networks), rules of behaviours among a group of friends (bridging norms), and sanctions that help to maintain the relationships with the powerful friends (linking sanctions). Some examples of the questions are "How many close friends live within a 15-20 minutes walk or 5-10 minutes drive, if any?" "Do you think that friendship is important to you?" "How many friends do you have?" "Do you feel that it is easy to make friends?" "Are there any norms of behaviours between you and your friends?" and "How often do you bully another child, such as saying nasty or unpleasant things to them, tease them a lot in

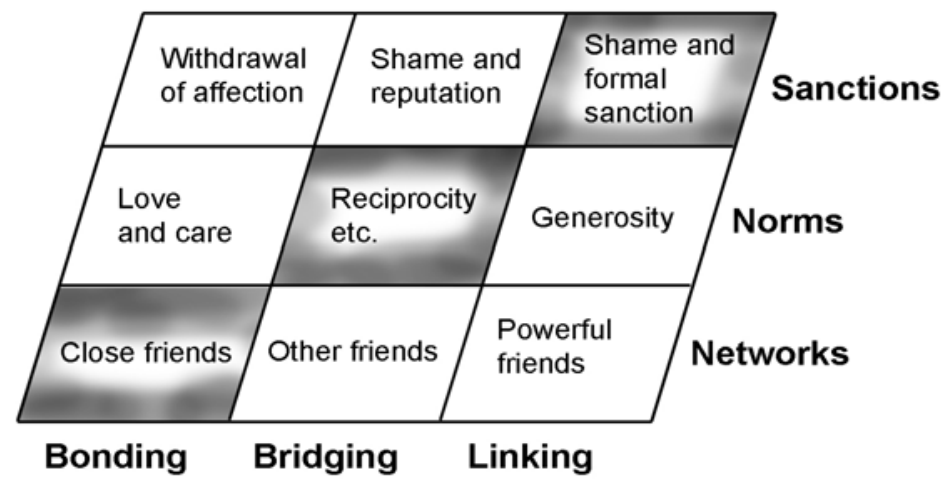

Figure 2. Three theoretical constructs were chosen to develop the Adolescent Friendship Social Capital Scale 
a nasty way, hit, kick, threaten, lock inside a room, send nasty notes, won't talk to them, etc?"

Through the first several interviews, the investigator found that the respondents felt difficult to talk about bullying (the sanctions to maintain the relationship with the powerful). The literature suggests that 'bullying behaviours' are frequently used by the powerful adolescents to maintain their status. The powerimbalance between the bullies and victims has been addressed by several previous studies (e.g., Carter, 2011; Cuadrado, 2011; Felix, Sharkey, Green, Furlong, \& Tanigawa, 2011). The bullies are normally physically stronger than victims (Lagerspetz, Bjorkqvist, Berts, \& King, 1982); and the victims typically show lower levels of self-esteem and are usually sensitive and quiet (Haynie et al., 2001). However, investigating bullying would possibly trigger emotional discomfort of the participants, as the adolescents who are involved in bullying behaviours are at risks to depression, ideation, and suicide attempts (Brunstein, Marrocco, Kleinman, Schonfeld, \& Grould, 2007). Due to ethical concerns, the Human Ethics Research Committee at the University of Sydney advised the investigator not to investigate bullying experiences of the respondents. Because of the above reasons, and because investigating 'bullying' was not the main purpose of this study, the investigator decided to delete the theoretical construct 'linking sanctions' from further investigation.

After deleting the theoretical construct 'linking sanctions', the remaining two theoretical constructs were 'bonding networks' and 'bridging norms'. In order to cover the linking social capital, and in order to collect information about sanctions, two more theoretical constructs were chosen: 'Bridging sanctions' and 'linking networks'. 'Bridging sanctions' refer to the punishments and rewards that help to maintain the norms and networks between an adolescent and other friends (apart from the close friends). As there was no power imbalance between the respondents and the 'other friends', the investigations on 'bridging sanctions' went well. 'Linking networks' refer to an adolescent's linkage with the powerful friends. Interviews with adolescents showed that the 'powerful kids' at school tended to be the popular ones, and the respondents had no difficulties talking about them.

Therefore, the chosen theoretical constructs were revised to bonding networks, bridging norms, bridging sanctions, and linking networks (as highlighted in Figure 3). The revised theoretical constructs still included the three types and three components of social capital, and their distributions in the model were still geometrically balanced. The revised theoretical constructs were considered good representation

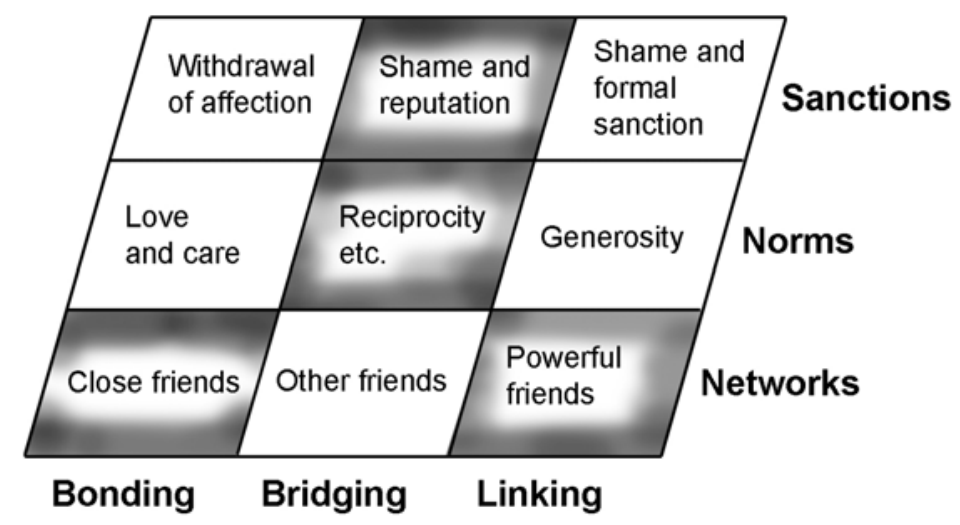

Figure 3. The revised four theoretical dimensions to develop the Adolescent Friendship Social Capital Scale 
of the concept of social capital. Reflecting the changes in the theoretical constructs, a modified set of interview questions were used in the following interviews. The question about 'bullying' was deleted, and a few new questions targeting at 'Bridging Sanctions' and 'Linking Networks' were added, such as "If you have done something seriously wrong to your friends, what do you think would happen?" "Do you think some kids are more powerful than others?" and "What kind if kids do you think are more powerful?”

As the interviews were semi-structured, there were flexibilities in the questions. The prepared questions could be modified during the interviews to reflect what the interviewees said, and new questions could be brought up during the interviews. For example, the questions "What kind of kids are more powerful" were asked during the first few interviews, but the children told the investigator that they thought 'popular' was a better word than 'powerful'. Therefore, in the following interviews, the question was changed to "What kind of kids are more popular”.

\section{Procedures}

Each interview took about one hour, and the interview conversations were audio-recorded. After each interview, the investigator briefly reviewed the field notes and the interview soundtracks. The reflections of the interview informed the questions and process of the next interview. During this iterative process, the themes started emerging and the items were generated. The generated items were checked and tested in the following interviews, in that the investigator asked the respondents to comment on the relevance and clarity of the scale items.

\section{Data Analysis}

The interview conversations were recorded during each interview, and then the conversations were digitalised and transcribed after each interview. The information in Chinese was translated into English. The investigator reviewed the interview transcripts, notes, and original recordings iteratively to absorb and deeply understand the significance of the data.

Ian Dey (1993) points out, "There is no one kind of qualitative data analysis, but rather a variety of approaches, related to the different perspectives and purposes of researchers". Therefore, qualitative strategies are characterised by diversity. In this study, the objective of data analysis was to generate a pool of candidate items for Adolescent Friendship Social Capital Scale. Two steps of data analysis were involved to serve this purpose: identifying themes and developing indicators.

Identifying themes. Themes offer descriptions of how people do or should behave (Rubin \& Rubin, 1995). Themes are the abstract constructs that investigators identify before, during and after data collection (Ryan \& Bernard, 2003). Themes in this study were identified both deductively and inductively.

For example, an important theme "popularity" emerged both from theory (i.e., deductively) and the data analysis (i.e., inductively). As shown in Figure 3, "linking networks" was one of the theoretical constructs chosen to develop indicators, which referred to an adolescent's linkage with the powerful friends.

In order to investigate the 'linking networks', the investigator asked questions such as "what kind of kids do you think are more powerful?” and "do you think some of your friends have more power than others?" However, the investigators found that the respondents did not use the word "power"; instead, they used "popular" and "popularity" to describe the power relationships. Some respondents gave a few examples, and some told stories to illustrate their opinions on popularity. For example:

Investigator: What kind of kids do you think are more powerful?

Sdyney-1: Having money, so that they can buy nice stuff and buy things for others. Some kids are rich, like, have 10 dollars 
pocket money every day, so that they can buy things for everybody at lunchtime, which make them popular everybody likes them.

Investigator: Do you think some friends have more power than others?

Sydney-5: No, en, I don't know if power is the right word, like, there are people who are extroverted and introverted, so there are people who are really loud and outgoing, and people who are kind of sit down and keep the force to the self...

Investigator: Do you think some people in school have more power than others?

Sydney-4: Yeah I do think...yeah, I do because, like, just for an example, there is this girl in the popular group called Amy. Now, Amy is gorgeous, like, she is really, really beautiful, like, she's got gorgeous brown hair, and gorgeous brown skin... and she is pretty, has bright blue eyes, got this job as a model - she actually does do modelling work - and, everyone, whether or not, you know, she's your friend or what, like, if she asks you to do something, you still do it.

Interviews with adolescents revealed that "popularity" referred to the status of the respondent in her of his friendship networks, which is consistent with previous studies (e.g., Berger \& Rodkin, in press; Shoulberg, Sijtsema, \& Murray-Close, 2011). As "popularity" fits into the theoretical dimension "linking networks”, it emerged as a theme supported by theory and empirical data. The indicators generated from the interviews to measure 'popularity' included 'having money' and 'outgoing'.

The similar data analysis process revealed three other themes of adolescent social capital: close friends, group rules, and group sanctions. These three themes fit into the theoretical constructs bonding networks, bridging norms, and bridging sanctions respectively. Therefore, the four identified themes represent the four revised theoretical constructs of social capital (which are highlighted in Figure 3).

The most important strength of this stage of data analysis is that the identified themes were informed by, and fitted into the theoretical basis of this study. Therefore, the initial construct validity was built into the scale through the data analysis process.

Developing indicators. The next step of data analysis was to develop indicators to measure the identified themes. Content analysis was conducted on the interview transcriptions. The contents that fitted into the identified themes were coded into short statements and listed under the aligned themes. For example, answering the question "norms of behaviour between you and your friends", two Chinese respondents and two Australian respondents mentioned "be happy". Therefore, an item "be happy" was listed under the theme bridging norms (group rules). Some other items to represent the theme bridging norms (group rules) included "trust”, "be nice", and "support each other". Using the same techniques, items for other themes were identified and coded.

\section{Results}

Twenty-six items emerged from interviews, organised in four theoretical constructs: Bonding networks (close friends), bridging norms (group rules), bridging sanctions (group sanctions), and linking networks (popularity). After that, these items were developed into short, clear, Likerttype statements. For example, the item "confident" was developed into a short statement "I am confident”. After identifying the 26 candidate items, a self-administered questionnaire was developed to evaluate the 26 adolescent social capital statements. The items were evaluated using five-point Likert scales anchored by $1=$ "strongly agree" and 5 = "strongly disagree" (as shown in Appendix 1). 


\section{Discussion}

\section{Strengths and Limitation of This Study}

The Adolescent Friendship Social Capital Scale developed in this study has a number of advantages over previous measures of an adolescent's friendship networks and friendship social capital. First, the structure of the scale is based on the theory of social capital, therefore demonstrates the connection between theory and measurement. This process also established the initial construct validity of the scale. Second, the scale items were developed from interviews with the adolescents, thus established the initial content validity. Third, the scale collects continuous data, which enables the performance of parametric statistical analysis.

The limitation of this scale is that it only measures four out of the nine theoretical constructions of an adolescent's friendship social capital. The four chosen theoretical constructs are considered good representation of the concept, in that they cover the three types (bonding, bridging, and linking) and three components of social capital (networks, norms, and sanctions). However, the scale will be stronger if it measures all of the nine theoretical constructs.

\section{Next Two Stages of Research}

Developing a psychometrically sound scale is a difficult and time-consuming process. It is suggested that three basic stages should be involved in the development of measures: (1) Item generation, (2) scale development, and (3) scale evaluation (Hinkin, 1995). The study reported in this paper is the first stage of developing a psychometrically sound measurement of an adolescent's friendship social capital: Item generation.

Several criteria have been proposed to assess the psychometric properties of measurement. For example, the American Psychological Association (APA) states that measures should demonstrate content validity, criterion-related validity, construct validity and internal consistency (American Psychological Association, 1985).

Content validity refers to the adequacy with which a measure assesses the domain of interest. Criterion-related validity pertains to the relationship between a measure and another independent measure. Construct validity is concerned with the relationship of the measure to the underlying attributes it is attempting to assess. Internal consistency refers to the homogeneity of the items in the measure of the extent to which items responses correlate with the total test score (Hinkin, 1995).

Initial construct and content validity have been built into the scale (as discussed in the Method section). However, in order to satisfy APA criteria for validity and reliability, two additional stages of investigation are necessary: Scale development and scale evaluation. The scale development study was finished in 2010. The author has conducted a cross-national survey that tested the scale on 166 high school students in Beijing and 234 high school students in Beijing. Exploratory factor analysis has been performed to eliminate unreliable items and improve the parsimony of the scale; and structural equation modeling has been conducted to test the structure of the scale. It is anticipated that the results of the scale development stage (ie., the cross-national survey) will be reported by the middle of 2012 .

The author is currently preparing for the scale evaluation study (i.e., the third stage) to assess the test-retest reliability and internal-consistency reliability; and improve the content and construct validity of the scale. For example, a panel of experts in adolescent studies will be invited to assess the content and construct validity of the scale (in light of the work by Sugiyama \& Moore, 2005). Moreover, the questionnaire will be administered on two occasions to a sample of respondents to assess the test-retest reliability.

\section{Conclusion}

A large volume of empirical studies have been carried out to investigate the relationships 
between adolescents' friendship networks and various cognitive, psychological and behavioural variables, such as academic achievement (e.g., Goza \& Ryabov, 2009; Riegle-Crumb \& Callahan, 2009), aggressive behaviours (e.g., Rose et al., 2004), substance and drug use (e.g., Kramer \& Vaquera, 2011; Pilkington \& Sharifullina, 2011), sexual activities (e.g., Udry \& Billy, 1987), and schoolto-work transition (e.g., Sletten, 2011). The measurement of the adolescent friendship networks in these studies have been inconsistent, therefore, the scale developed in this study could be a useful tool to assist the investigation in the future. In addition, this scale could assist the exploration of a range of interesting research questions such as the relationship between adolescent social capital and their psycho-social well-being, adolescent social capital and their neighbourhood environment, differences in adolescent social capital due to family's socioeconomic backgrounds, etc. For example, the experiences of immigrant children and youth have been the interest of study of many scholars (e.g., Hagen, MacMillan, \& Wheaton, 1996; Peguero, 2009; Suarez-Orozco, Rhodes, \& Milburn, 2009). The scale developed in this study could help to investigate the loss of adolescent social capital due to family immigration, the rebuilt of social capital through youth programs, and the comparison of social capital between first-generation and secondgeneration immigrant adolescents.

However, as discussed in a previous section, additional studies need to be performed to improve the reliability ad validity of the scale, before it can be used as a reliable and valid tool to measure adolescent friendship social capital.

Acknowledgements: This research was supported by an Endeavour International Postgraduate Research Scholarship. My supervisor, Emeritus Professor Gary Moore, offered constant academic and emotional support throughout the research process. I want to thank the adolescents who participated in this research.

\section{References}

American Psychological Association. (1985). Standards for educational and psychological testing. Washington, DC: American Psychological Association.

Berger, C., \& Rodkin, P. C. (in press). Group influences on individual aggression and prosociality: Early adolescents who change peer affiliations. Social Development.

Bernt, T. J. (1989). Obtaining support from friends during childhood and adolescence. In D. Belle (Ed.), Children's social networks and social supports (pp.308-331). New York: John Wiley \& Sons.

Bourdieu, P. (1972). Esquisse d'une théorie de la pratique. Cambridge: Cambridge University Press.

Bourdieu, P. (1986). The forms of capital. In J. G. Richardson (Ed.), Handbook of theory and research for the sociology of education (pp. 241-258). New York: Greenwood Press.

Brien, A., \& Smallman, C. (2011). The respected manager: The organisational social capital developer. International Journal of Hospitality Management, 30(3), 639-647.

Brunstein, K. A., Marrocco, F., Kleinman, M., Schonfeld, I. S., \& Grould, M. S. (2007). Bullying, depression, and suicidality in adolescents. Journal of the American Academy of Child and Adolescent Psychiatry, 46(1), 40-49.

Bukowski, W. M., Hoza, B., \& Boivin, M. (1994). Measuring friendship quality during pre- and early adolescence: The development and psychometric properties of the Friendship Qualities Scale. Journal of Social and Personal Relationships, 11, 471-484.

Burt, R. S. (2000). The network structure of social capital. In B. M. Staw \& R. I. Sutton (Eds.), Research in organizational behavior (Vol. 22, pp. 345-423). Greenwich: JAI Press.

Carter, S. (2011). Bullies and power: A look at the research. Issues in Comprehensive Pediatric Nursing, 34(2), 97-102.

Chen, X., Stanton, B., Gong, J., Fang, X., \& Li, X. (2009). Personal social capital scale: An 
instrument for health and behavioral research. Health Education Research, 24(2), 306-317.

Cillessen, A. H. N., Jiang, X. L., West, T. V., \& Laszkowski, D. K. (2005). Predictors of dyadic friendship quality in adolescence. International Journal of Behavioral Development, 29(2), 165-172.

Coleman, J. S. (1988). Social capital in the creation of human capital. American Journal of Sociology, 94(Supplement), 95-120.

Coleman, J. S. (1990). The foundations of social theory. Cambridge, MA: Harvard University Press.

Coolican, H. (2004). Research methods and statistics in psychology (4th edition). London: Hodder \& Stoughton.

Cuadrado, G. I. (2011). Divergence in aggressors' and victims' perceptions of bullying: A decisive factor for differential psychosocial intervention. Children and Youth Services Review, 33(9), 1608-1615.

Devellis, R. F. (1991). Scale development. New Delhi: Sage.

Dey, I. (1993). Qualitative data analysis: A user-friendly guide for social scientists. London: Routledge.

Felix, E. D., Sharkey, J. D., Green, J. G., Furlong, M. J., \& Tanigawa, D. (2011). Getting precise and pragmatic about the assessment of bullying: The development of the California Bullying Victimization Scale. Aggressive Behavior, 37(3), 234-247.

Field, J. (2003). Social capital. London \& New York: Routledge.

Ginsberg, D., Gottman, J. M., \& Parker, J. G. (1986). The importance of friendship. In J. M. Gottman \& J. G. Parker (Eds.), Conversations of friends: Speculations on affective development (pp.3-50). New York: Cambridge University Press.

Goza, F., \& Ryabov, I. (2009). Adolescents' educational outcomes: Racial and ethnic variations in peer network importance. Journal of Youth and Adolescence, 38, 12641279.

Granovetter, M. S. (1973). The strength of weak ties. American Journal of Sociology, 78, 1360-1380.
Granovetter, M. S. (1985). Economic action and social structure: The problem of embeddedness. American Journal of Sociology, 91, 481-510.

Grant, J. S., \& Davis, L. L. (1997). Focus on quantitative methods: Selection and use of content experts for instrument development. Research in Nursing \& Health, 20, 269-274.

Hagen, J., MacMillan, R., \& Wheaton, B. (1996). New kid in town: Social capital and the life course effects of family migration on children. American Sociological Review, 61(3), 368-385.

Halpern, D. (2005). Social capital. Cambridge, UK: Polity Press.

Hamm, J., Farmer, T. W., Dadisman, K., Gravelle, M., \& Murray, A. R. (2011). Teacher's attunement to students' peer group affiliation as a source of imporoved student experiences of the school socio-affective context following the middle school transition. Journal of Applied Developmental Psychology, 32(5), 267-277.

Haynie, D. L., Nansel, T., Eitel, P., Crump, A. D., Saylor, K., Yu, K., \& Simons-Morton, B. (2001). Bullies, victims, and bully/victims: Distinct groups of at-risk youth. The Journal of Early Adolescence, 21(1), 29-49.

Hinkin, T. R. (1995). A review of scale development practices in the study of organizations Journal of Management, 21(5), 967-988.

Kramer, R. A., \& Vaquera, E. (2011). Who is really doing it? Peer embeddedness and substance use during adolescence. Sociological Perspectives, 54(1), 37-58.

Lagerspetz, K. M., Bjorkqvist, K., Berts, M., \& King, E. (1982). Group aggression among school children in three schools. Scandinavian Journal of Psychology, 23, 4552.

Lin, N. (2001). Social capital: A theory of social structure and action. Cambridge: Cambridge University Press.

Moore, G. T., \& Sugiyama, T. (2007). The Children's Physical Environment Rating Scale (CPERS): Reliability and validity for assessing the physical environment of early 
childhood educational facilities. Children, Youth and Environment, 17(4), 24-53.

Parker, J. G., \& Asher, S. R. (1993). Friendship and friendship quality in middle childhood: Links with peer group acceptance and feelings of loneliness and social dissatisfaction. Developmental Psychology, 29, 611-621.

Peguero, A. A. (2009). Victimizing the children of immigrants: Latino and Asian American student victimization. Youth and Society, 41(2), 186-208.

Pilkington, H., \& Sharifullina, E. (2011). The mutual extraction industry: Drug use and the normative structure of social capital in the Russian far north. International Journal of Drug Policy, 20, 251-260.

Plata, M., \& Trusty, J. (2005). Effect of socioeconomic status on general and at-risk high school boys' willingness to accept samesex peers with LD. Adolescence, 40(157), 4766.

Putnam, R. D. (1995). Bowling alone: America's declining social capital. Journal of Democracy, 6(1), 65-78.

Putnam, R. D. (2000). Bowling alone: The collapse and revival of American community. New York: Simon and Schuster.

Putnam, R. D., Leonardi, R., \& Nanetti, R. (1993). Making democracy work: Civic traditions in modern Italy. Princeton, NJ: Princeton University Press.

Riegle-Crumb, C., \& Callahan, R. M. (2009). Exploring the academic benefits of friendship ties for Latino boys and girls. Social Science Quarterly, 90(3), 611-631.

Rose, A. J., \& Asher, S. R. (1999). Children's goals and strategies in response to conflicts within a friendship. Developmental Psychology, 35, 69-79.

Rose, A. J., Swenson, L. P., \& Carlson, W. (2004). Friendships of aggressive youth: Considering the influences of being disliked and of being perceived as popular. Journal of Experimental Child Psychology, 88, 25-45.

Rubin, H. J., \& Rubin, I. S. (1995). Qualitative interviewing: The art of hearing data. London: Sage Publications.
Ryabov, I. (2011). Adolescent academic outcomes in school context: Network effects reexamined. Journal of Adolescence, 34(5), 915-927.

Ryan, G. W., \& Bernard, H. R. (2003). Techniques to identify themes in qualitative data. Field Methods, 15(1), 85-109.

Schaefer-McDaniel, N. J. (2004). Conceptualizing social capital among young people: Towards a new theory. Children, Youth and Environment, 14(1), 140-150.

Seiffge-Krenke, I. (1993). Close friendship and imaginary companions in adolescence. New directions for child development, 60, 73-87.

Shoulberg, E. K., Sijtsema, J. J., \& MurrayClose, D. (2011). The association between valuing popularity and relational aggression: The moderating effects of actual popularity and physiological reactivity to exclusion. Journal of Experimental Child Psychology, 110, 20-37.

Sletten, M. A. (2011). Long-term benefits of social ties to peers - even among adolescents with 'risky' friendships? Journal of Youth Studies, 14(5), 561-585.

Slund, C., Starrin, B., \& Nilsson, K. W. (2010). Social capital in relation to depression, musculoskeletal pain, and psychosomatic symptoms: A cross-sectional study of a large population-based cohort of Swedish adolescents. BMC Public Health, 10, 715.

Suarez-Orozco, C., Rhodes, J., \& Milburn, M. (2009). Unraveling the immigrant paradox: Academic engagement and disengagement among recently arrived immigrant youth. Youth and Society, 41(2), 151-185.

Sugiyama, T. \& Moore, G. T. (2005). Content and construct validity of the Early Childhood Physical Environment Rating Scale (ECPERS). In H. Chaudhury (Ed.), Design for diversity: Proceedings of the 36th annual conference of the Environmental Design Research Association (pp.32-37). Edmond, OK: Environmental Design Research Association.

Udry, J. R., \& Billy, J. O. G. (1987). Initiation of coitus in early adolescence. American Sociological Review, 52(6), 841-855. 
von dem Knesebeck, O., Dragano, N., \& Siegrist, J. (2005). Social capital and selfrated health in 21 European countries. GMS Psycho-Social Medicine, 2, Doc02.

Woolcock, M. (2001). The place of social capital in understanding social and economic outcomes. Isuma: Canadian Journal of Policy Research, 2(1), 1-7.

Wu, Q., Palinkas, L. A., \& He, X. (2011). Social capital in promoting the psychosocial adjustment of Chinese migrant children: Interaction across contexts. Journal of Community Psychology, 39(4), 421-442.
Youniss, J., \& Smollar, J. (1985). Adolescent relations with mothers, fathers, and friends. Chicago: University of Chicago Press.

Zimmermann, P. (2004). Attachment representations and characteristics of friendship relations during adolescence. Journal of Experimental Child Psychology, 88, 83-101.

Received September 30, 2011

Revision Received November 25, 2011

Accepted December 15, 2011 


\section{Appendix 1: Adolescent Friendship Social Capital Scale}

\section{Bonding Networks}

You might have a lot of friends - some of them are very close to you (they are your "best friends" or "close friends”). Please tell me something about your Close Friends.

$$
\begin{array}{lllllll}
\text { Strongly } & -2 & -1 & 0 & 1 & 2 & \begin{array}{c}
\text { Strongly } \\
\text { Agree }
\end{array}
\end{array}
$$

1. My close friends give me support and encouragement

2. My close friends would see that I was taken care of

3. My close friends can be relied on no matter what happens

\section{Bridging Norms}

Apart from your close friends, you have some other friends. There might be a Group of Friends that you hang out a lot with. The items listed below are some possible "unspoken rules" between you and your "Group of Friends". Please indicate the importance of each of them.

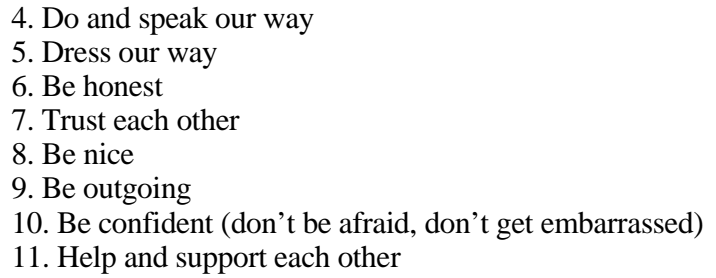

\section{Bridging Sanctions}

If you behave yourself in accordance to these "unspoken rules", what do you expect?

12. I will be accepted by our group

$$
\begin{array}{ccccccc}
\begin{array}{c}
\text { Not } \\
\text { Possible }
\end{array} & 1 & 2 & 3 & 4 & 5 & \begin{array}{c}
\text { Very } \\
\text { Possible }
\end{array}
\end{array}
$$

13. I will get more recognition

14. I will be liked more

If you seriously break these "unspoken rules” between you and this group of friends, what might happen?

15. My friends will not hang out with me any more

$$
\begin{array}{ccccccc}
\begin{array}{c}
\text { Not } \\
\text { Possible }
\end{array} & 1 & 2 & 3 & 4 & 5 & \begin{array}{c}
\text { Very } \\
\text { Possible }
\end{array}
\end{array}
$$

16. I will not be invited anymore

\section{Linking Networks}

How would you describe yourself?

17. I participate a lot in sports or outdoor activities

$$
\begin{array}{ccccccc}
\begin{array}{c}
\text { Strongly } \\
\text { Disagree }
\end{array} & -2 & -1 & 0 & 1 & 2 & \begin{array}{c}
\text { Strongly } \\
\text { Agree }
\end{array}
\end{array}
$$

18. I do well in study

19. I wear clothes and use things with well-known labels

20. I treat people nicely

21. I am confident

22. Other kids like to hang out with me

23. I am unique

24. I have a talent (such as singing, dancing, etc)

25. I have money

26. I am popular 